\title{
INFLUÊNCIA DO PEITORIL DE JANELAS NA LUZ NATURAL E VISÃO DE CÉU EM ENFERMARIAS
}

\section{INFLUENCE OF THE WINDOW SILL IN NATURAL LIGHT AND VISION OF SKY IN HOSPITAL WARDS}

\author{
Pedro Vitor Sousa Ribeiro 1 \\ Universidade Federal de Alagoas, Maceió, AL, Brasil, pedro.ribeiro@fau.ufal.br \\ Danielle Maria Lamenha Santos ${ }^{2}$ \\ Universidade Federal de Alagoas, Maceió, AL, Brasil, danielle.lamenha@fau.ufal.br \\ Lara Torres de Melo Vasconcellos 3 \\ Universidade Federal de Alagoas, Maceió, AL, Brasil, laratmelo@gmail.com \\ Fernando A. de M. Sá Cavalcanti ${ }^{4}$ \\ Universidade Federal de Alagoas, Maceió, AL, Brasil, fernando.antonio@fau.ufal.br \\ Ricardo Carvalho Cabús ${ }^{5}$ \\ Universidade Federal de Alagoas, Maceió, AL, Brasil, r.cabus@ctec.ufal.br
}

\begin{abstract}
Resumo
A configuração das janelas pode influenciar na luminosidade do ambiente e na comunicação visual de pacientes com o meio exterior. Para o bom aproveitamento dos benefícios da janela em ambientes hospitalares é importante verificar a contribuição da altura do peitoril. Esta pesquisa investiga a influência do peitoril no desempenho luminoso e na visão de céu em enfermarias hospitalares na cidade de Maceió, Alagoas. O objeto empírico compreende seis enfermarias femininas com mesmo desenho de janelas, mas com posição vertical e orientação distintas. Foi feita uma análise comparativa entre duas posições verticais da janela: alta e baixa, por meio de simulação computacional usando o software TropLux. Os resultados mostram que nos espaços analisados há ocorrência de desconforto devido ao excesso de luz natural, especialmente de luz direta do céu e do sol, causando ofuscamento. A falta de protetores solares nas aberturas faz com que haja grande quantidade de luz dentro do ambiente hospitalar, que é menos expressiva nas enfermarias que têm janelas voltadas para o vazio interno da edificação.
\end{abstract}

Palavras-chave: Iluminação natural. Arquitetura hospitalar. Conforto luminoso.

\begin{abstract}
Window configuration can influence room brightness and the visual communication of hospital patients with the outside. It is essential to verify the contribution of the sill's height for the proper use of the benefits of the window in hospital admission spaces. This research investigates the influence of the sill in the luminous performance and promotion of the outward view in hospital wards in Maceio, Alagoas. The empirical object comprises six female wards with the same window design, but with different vertical position and orientation. The research method deals with a comparative analysis between two vertical positions of the window: high and low, through computer simulation using TropLux software. The results show that the analyzed wards have discomfort due to the excess of natural light, especially direct light from the sky and the sun, causing glare. The lack of sunscreens in the openings results in a large amount of light inside the hospital environment, which is less expressive in the wards that have windows facing the building's internal void.
\end{abstract}

Keywords: Daylighting. Hospital architecture. Luminous comfort.

How to cite this article:

RIBEIRO, P. V. S.; SANTOS, D. M. L.; VASCONCELLOS, L. T. DE M.; CAVALCANTI, F. A. DE M. S.; CABÚS, R. C. Influência do peitoril de janelas na luz natural e visão de céu em enfermarias. PARC Pesquisa em Arquitetura e Construção, Campinas, v. 11, p. e020009, 13 jul. 2020. DOI: https://doi.org/10.20396/parc.v11i0.8654728 


\section{Introdução}

A iluminação natural é um importante atributo ambiental. Seu uso é justificado em função dos benefícios à saúde humana, bem-estar e desempenho nas atividades. (HOPKINSON; PETHERBRIDGE; LONGMORE, 1975; BAKER, STEMMERS, 2002; BOYCE, 2003;). Hopkinson, Petherbridge e Longmore (1975) explicitam que, para prover um ambiente bem iluminado, é importante considerar níveis adequados de iluminação para garantir a execução de tarefas de forma eficiente e segura, além de promover um ambiente visual agradável.

A disponibilidade da luz natural depende de fatores externos como clima, localização geográfica, qualidade do ar, entre outros. Aspectos como a intensidade e distribuição da luz em um ambiente interno estão relacionados, entre outros fatores como características das superfícies e geometria do ambiente, com os atributos projetuais das janelas, ou seja, seu posicionamento, dimensões e orientação geográfica (BAKER; STEEMERS 2002).

A principal função da janela está em prover o acesso à luz natural e proporcionar aos ocupantes o contato visual com o mundo exterior (HOPKINSON; PETHERBRIDGE; LONGMORE, 1975). Para Lam (1997), o contato visual com o exterior é uma necessidade biológica de informação visual e o ser humano, ao ser privado desse contato, entra em situação de desconforto. Para ambientes de longa permanência, como as enfermarias hospitalares, estes aspectos são bastante relevantes, pois influenciam na recuperação do paciente (ULRICH, 2002). Grandes, pequenas, baixas ou altas, ao comporem as fachadas, as aberturas interferem na ambiência e no conforto visual do paciente e a corrente padronização dos projetos hospitalares não costuma priorizar as aberturas e a vista para o exterior.

Aberturas laterais com peitoris baixos proporcionam iluminação pouco uniforme, com risco de ofuscamento por se situarem na linha de visão. Por outro lado, permitem contato visual com a paisagem. Em contrapartida, janelas com peitoris altos propiciam um maior alcance na distribuição da luz e maior uniformidade, diminuindo a possibilidade de ofuscamento. Assim, este estudo tem o intuito de contribuir com a discussão sobre a qualidade dos espaços de internação hospitalar buscando investigar a influência da altura do peitoril da janela no desempenho luminoso e na visão de céu do paciente que utiliza uma enfermaria-

\section{A iluminação natural em hospitais}

O século XVIII marca o início do hospital terapêutico (FOUCAULT, 1979,1998). A partir de então os índices de cura das unidades hospitalares são relacionados a questões espaciais: número de leitos, ventilação e iluminação natural. Nesta época, grandes janelas eram usadas para o acesso à luz solar e trocas de ar interno. A descoberta da luz elétrica e o forte adensamento urbano tiveram várias implicações na arquitetura hospitalar, entre elas espaços desprovidos de luz natural e sem aberturas para o meio externo, já que a iluminação artificial permitia o atendimento a qualquer hora do dia e da noite (MIQUELIN, 1992; MONTEIRO, 2001; TOLEDO, 2006).

Diversas pesquisas comprovam a necessidade e importância da luz solar nos espaços de longa permanência. É importante notar que a luz influencia o relógio biológico, contribuindo para a regulação endócrina, do estresse e da fadiga (MARTAU, 2008). Em ambientes internos, independente do seu uso, os usuários procuram as janelas em busca da iluminação natural, por sua qualidade e pela vista exterior, em momentos de fuga da realidade interna, descanso mental e emocional (FERNANDES, 2016). A mesma 
autora afirma ainda que a permanência em ambientes com vista para o exterior reduz a percepção dos efeitos do ofuscamento pelo usuário.

Durante muito tempo a quantidade da luz no ambiente interno foi o critério de projeto mais adotado em ambientes hospitalares. Atualmente questões como o comportamento da luz e a comunicação visual com o meio exterior têm exercido forte influência no conforto ambiental. Contudo, as normas e regulamentações acerca da iluminação ainda balizam os projetos de arquitetura e iluminação por índices quantitativos.

Embora haja divergência nas normas quanto aos índices adequados de iluminação, a presença da luz natural e dos raios solares nestes ambientes torna-se particularmente importante porque dentre os benefícios da luz natural está a sincronização da fisiologia humana. Uma vez que nos hospitais o principal objetivo é o restabelecimento dos enfermos, a iluminação natural é, portanto, fator determinante de saúde (PECCIN, 2002).

A norma brasileira para iluminação de ambientes de trabalho NBR ISO/CIE 8.995-1 (ABNT, 2013b), indica os valores mínimos de iluminância para tarefas em áreas internas de trabalho, designando para ambientes de internação hospitalar coletivo (enfermarias), objeto de estudo deste trabalho, os seguintes valores de iluminância mantida: para iluminação geral $100 \mathrm{~lx}$, para iluminação de leitura e para exames simples $300 \mathrm{~lx}$.

\section{A importância da janela em ambientes hospitalares}

O uso da luz natural em edifícios oferece senso de orientação, de tempo e das condições meteorológicas a seus ocupantes, além de promover ambientes internos potencialmente mais confortáveis e atrativos (BAKER; FANCHIOTTI; STEEMERS, 1998).

Desde os primórdios do edifício hospitalar predomina o uso de aberturas laterais para o provimento da luz solar. As janelas têm várias funções nesse tipo de edifício, destacando-se neste estudo a atribuição de prover o ambiente com luz natural e permitir visão para o exterior.

Ulrich (1984) pesquisou a influência da vista para o exterior no tempo de internação dos pacientes e concluiu que pacientes em Unidades de Tratamento Intensivo (UTI) sem vista para o exterior permanecem mais tempo internados do que pacientes que podem ver o exterior através de uma janela.

Malkin (1992) reforça que o contato com o exterior proporciona a continuidade no ritmo biológico humano pela passagem do tempo, das horas do dia e das estações. Tal contato estabelece também referenciais de orientação e mudança visual aos pacientes e funcionários.

Estudos feitos por Peter Boyce apontam que a existência de janelas em locais de permanência em instalações de saúde reduz a ocorrência de dor, febre, depressão pósoperatório, melhoram o ciclo do sono e auxiliam na recuperação de tratamentos prolongados, como o do câncer (BOYCE, 2010). Santos (2009), ao pesquisar a satisfação visual do paciente em enfermarias, verificou que a necessidade de maior destaque era a de um peitoril que possibilitasse ao paciente acamado ver o exterior a partir do próprio leito. Estudos realizados em hospitais para detentos verificaram que em ambientes onde as janelas permitiram a vista de colinas e campos os pesquisados ficaram significativamente menos doentes e influenciou na recuperação de pacientes em UTI (HELLINGA, 2013) 
Para Ulrich (2002) é importante ressaltar que os benefícios associados às vistas se estendem aos funcionários, como médicos e pessoal de enfermagem, exibindo níveis mais baixos de estresse e maior desempenho em espaços iluminados naturalmente e com vistas de janelas.

Loe e Davidson (1998) apud Costi (2001) relembram que pesquisas feitas sobre a importância da luz natural na recuperação de pacientes demonstraram que a luz solar era a preferida porque as pessoas sentiam-se melhor com algum grau de variação na iluminância. Conforme Rasmussen (2002), o estado de espírito altera-se com a luz cambiante.

De maneira geral, as dimensões e altura das janelas modificam a distribuição de luz no ambiente. O posicionamento de janelas no ambiente designa situações luminosas distintas: a) janelas baixas promovem iluminação pouco uniforme com risco de ofuscamento por se situarem na linha de visão, contudo otimizam o contato visual com a paisagem; b) Janelas altas propiciam um maior alcance na distribuição da luz e maior uniformidade, diminuindo a possibilidade de ofuscamento mas, por estarem acima do campo visual, não otimizam a visão exterior.

Ghisi, Tinker e Ibrahim (2005), Fernandes (2009), Lima (2010) e Lamberts, Dutra e Pereira (2014) ressaltam que janelas amplas podem proporcionar níveis mais altos de iluminação natural e melhor vista para o exterior, mas também podem causar desconforto e aumento do consumo de energia. Diante deste quadro, conhecer o panorama luminoso proporcionado pelo posicionamento das janelas poderá contribuir para uma melhor discussão sobre decisões de projetos arquitetônicos para ambientes com pacientes acamados.

\section{Metodologia}

A descrição da metodologia será dividida em duas etapas, inicialmente será apresentado o objeto de estudo e posteriormente as ferramentas utilizadas.

\section{Objeto de estudo: Hospital da Mulher em Maceió-AL}

O objeto desta pesquisa faz parte das instalações de um Hospital Público Estadual, localizado na cidade de Maceió, Alagoas. Trata-se de um edifício vertical com oito pavimentos e capacidade de 127 leitos. As enfermarias ocupam o terceiro e quarto pavimentos do edifício. $O$ edifício está localizado em um bairro consolidado da cidade, em que predominam edificações de até dois pavimentos, fazendo com que não haja sombreamento nas fachadas. Até a elaboração deste artigo, o edifício encontrava-se em obras na fase de conclusão dos acabamentos internos.

A primeira etapa na avaliação do desempenho luminoso do objeto de estudo foi a seleção de enfermarias com características distintas de iluminação natural. Na Figura 1 estão destacadas as quatro salas escolhidas. As enfermarias ginecológicas (E-1 e E-3) são destinadas a pacientes em observação, enquanto as obstetrícias (E-2 e E-4) são destinadas a mulheres em estado puerperal.

Os critérios para a escolha das quatro enfermarias destacadas foram a possibilidade de visão do exterior e as situações mais desfavoráveis à iluminação natural. Duas situações merecem destaque: as enfermarias 1 a 3 possuem janelas voltadas para o exterior e a janela da enfermaria 4 está voltada para um vazio no centro da edificação.

As enfermarias 1 e 3 têm dimensões de 6,22 m x 5,10 m. As janelas estão posicionadas na parede de menor dimensão e ambas possuem quatro leitos. As enfermarias 2 e 4 têm dimensões de 5,24 m x 3,92 m. A janela está posicionada na menor dimensão e ambas 
possuem dois leitos. As janelas das enfermarias 1 a 3 são altas, com 1,95 $\mathrm{m}$ de peitoril e 1,20 $\mathrm{m}$ de altura, já a da enfermaria 4 possui 1,10 $\mathrm{m}$ de peitoril e 1,70 $\mathrm{m}$ de altura.

Figura 1 - Enfermarias selecionadas para a avaliação do desempenho luminoso. As cores utilizadas destacam os elementos de parede (Verde), janela (Vermelho), porta principal (Azul) e numeração dos leitos (Roxo)

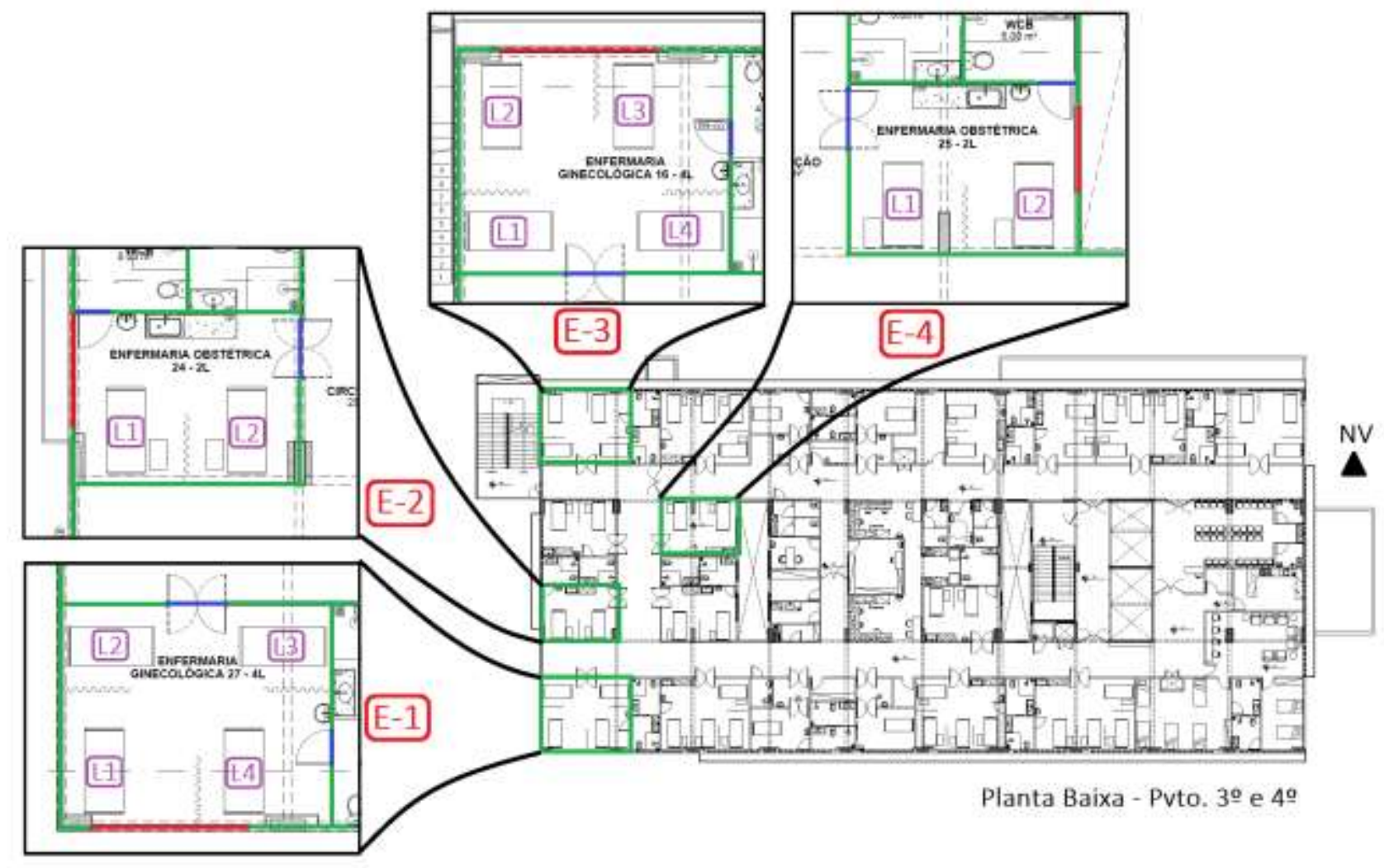

Fonte: os autores.

Os acabamentos internos para as seis enfermarias são: piso em cerâmica branca e tinta branco neve nas paredes e teto. As janelas possuem caixilho em alumínio e vidro incolor.

Uma das características mais evidentes dos ambientes analisados, principalmente nos modelos E-1 a E-3, é a presença de janelas com peitoril alto. Para fins de comparação, as três enfermarias do grupo foram estudadas em sua situação normal (modelos com terminação $\mathrm{N}$ ) e em uma situação proposta de alteração, com as janelas em altura que permitem a visão do entorno pelos usuários (modelos com terminação $\mathrm{M}$ ). Os dois grupos de modelos foram avaliados em relação à disponibilidade e à qualidade da iluminação no ambiente utilizando os índices de desempenho citados no próximo item.

\section{Ferramentas e métodos}

Estudos apontam que apenas uma análise quantitativa da iluminâncias de um determinado ambiente não é o suficiente para caracterizá-lo visualmente, necessitando também de aspectos relacionados à qualidade (KREMER, 2002). Desta forma, as métricas de análise utilizadas neste trabalho foram selecionadas levando em conta tanto a questão quantitativa como a questão qualitativa. São elas: Iluminância Média (Em) Uniformidade da lluminância (Um), Iluminância Útil de Luz Natural (IULN), Exposição Solar Anual (ESA) e Janela de Céu Preferível (JCP).

A iluminância é o parâmetro básico na análise do desempenho luminoso de ambientes segundo a norma brasileira para iluminação natural NBR 15.215, partes 2 a 4, (ABNT, 2005a; 2005b; 2005c) e a norma de desempenho das edificações NBR 15.575 (ABNT, 2013a). Normas de iluminação artificial, como a ISO/CIE 8.995-1 (ABNT, 2013b), também 
adotam esse índice como parâmetro de avaliação do desempenho luminoso de ambientes internos. A Em pode ser calculada a cada instante no plano de trabalho, mas para fins de comparação, tendo em vista os dados anualizados, foi utilizada a média sazonal (Ems).

Dentre os aspectos relacionados à qualidade visual, é possível destacar a distribuição de iluminâncias e sua variação no ambiente. Uma grande amplitude desses valores gera uma distribuição irregular e, consequentemente, desconforto visual (KREMER, 2002). Segundo a ISO/CIE 8.995-1 (ABNT, 2013b), a uniformidade pode ser definida como a razão entre a iluminância mínima e a iluminância média, onde, quanto mais próximos de 1 , mais uniforme.

Por se tratar de um estudo de enfermaria hospitalar, onde há atividades espalhadas por todo o ambiente, a área considerada para o trabalho foi o espaço interno do local por completo. O valor de referência adotado pela NBR ISO/CIE 8.995-1 (ABNT,2013b) é de $0,7(70 \%)$, entretanto ele não será adotado no estudo por ser um valor muito alto para iluminação natural (MANGKUTO; ROHMAH; ASRI, 2016). Utilizando a mesma lógica de agrupamento da Em, foi utilizada a média sazonal (Ums) como ferramenta de comparação entre os modelos analisados e propostos.

A Iluminância Útil de Luz Natural (IULN), proposta por Nabil e Mardaljevic (2005), permite conhecer a frequência de ocorrência dos níveis de luz natural dentro de determinadas faixas, onde são especificadas as iluminâncias úteis a serem adotadas nos planos de trabalho, fazendo uso de valores absolutos atribuídos às iluminâncias mínimas e máximas. Tais valores fazem referência à ocorrência anual em um plano de trabalho em um intervalo considerado "útil", apontando para a possibilidade de existir iluminâncias muito baixas ou muito elevadas, o que pode proporcionar desconforto visual e térmico. Importante destacar que a métrica IULN foi proposta para ambientes de escritórios, entretanto encontram-se algumas aplicações desta em ambientes hospitalares, como nos trabalhos de Medeiros (2015) e Eisazadeh, Allacker e Troyer (2019).

De acordo com Nabil e Mardaljevic (2005) a faixa de iluminância considerada "útil" está compreendida entre $100 \mathrm{~lx}$ e $2000 \mathrm{~lx}$, onde valores abaixo de $100 \mathrm{~lx}$ (faixa 1 < $100 \mathrm{~lx}$ ) são considerados insuficientes; valores entre $100 \mathrm{~lx}$ a $500 \mathrm{~lx}(100 \mathrm{~lx}$ < faixa 2 < $500 \mathrm{~lx}$ ) são considerados aceitáveis/eficazes, podendo haver a necessidade de complementação com luz artificial; valores dentro do intervalo de $500 \mathrm{~lx}$ a $2.000 \mathrm{~lx}$ (500 lx < faixa $3<2000$ Ix) são considerados aceitáveis; e, acima de $2.000 \mathrm{~lx}$ (2.000 Ix < faixa 4), excessivos. O limite de $2.000 \mathrm{Ix}$ foi posteriormente ampliado pelos autores para $3.000 \mathrm{Ix}$ (MARDALJEVIC et al., 2011). Mardaljevic et al. (2012) destacam que tais valores de referência estabelecidos nas quatro faixas de iluminâncias podem ser alterados conforme a necessidade do pesquisador. Este estudo considera, a partir de valores estabelecidos pela norma NBR ISO/CIE 8.995-1 (ABNT, 2013b), a faixa 2 (aceitável/eficaz), entre 100 lx e 300 lx, como favorável ao desenvolvimento das atividades no ambiente em estudo.

É importante ressaltar que os limitantes de IULN apresentados pelos autores que desenvolveram a métrica foram definidos para situações de altas latitudes, de clima temperado. Dias et al. (2018), ao avaliarem a IULN aplicada no clima tropical, apontam que o intervalo convencional desconsidera situações de grande luminosidade, comuns no clima tropical. Indicam ainda que são necessários mais estudos sobre os limitantes a fim de ampliá-los para o contexto climático tropical.

Com objetivo de auxiliar no limite da incidência direta da luz solar no espaço, buscando evitar desconforto visual e térmico, a Exposição Solar Anual (ESA) consiste em 
descrever o potencial de desconforto visual em ambientes internos e computar o percentual deste ambiente que excede o valor de $1.000 \mathrm{~lx}$, para iluminância da luz solar direta, por mais de 250 horas do ano, possuindo o limite de, no máximo, 10\% da área analisada. Essa métrica foi reconhecida pelo Comitê de lluminação Natural da IES (Iluminating Engineering Society) e divulgada por meio da norma LM 83-12 (IES, 2012).

A Janela de céu preferível, proposta por Leder (2007), é um parâmetro de controle do acesso à luz natural no meio urbano que pode garantir ao meio interno um bom aproveitamento da luz natural e visibilidade do céu. A autora afirma ainda que a janela de céu preferível compreende três aspectos principais: a) a contribuição relativa de luz das diferentes parcelas da abóbada celeste; b) o efeito redutor do cosseno do ângulo de incidência e c) a frequência de visibilidade. Para a autora, a integração desses aspectos é responsável pela caracterização do potencial de iluminação da abóbada celeste no ambiente interno. Dessa forma, este método permite caracterizar o percentual de áreas do plano de trabalho horizontal de um ambiente interno com visão de céu.

Para fins de análise, as enfermarias foram divididas em dois grupos: Grupo 1 com as salas 1 a 3, que possuem janelas com visão do exterior, e o grupo $2 \mathrm{com}$ a sala 4 , que possui janela sem visão para o exterior. Os aspectos analisados em cada grupo são apresentados na Tabela 1. Apenas o grupo 1 será analisado quanto a visão de céu (JCP) utilizando a máscara de sombra do paciente em decúbito dorsal.

As simulações foram realizadas no software de simulação em iluminação natural TropLux. Este software permite simular a iluminação natural com precisão dos aspectos climáticos e arquitetônicos, permitindo modelagem de geometrias complexas (CABUS, 2005). O processamento foi realizado para todos os dias do ano das $7 \mathrm{~h}$ às $17 \mathrm{~h}$, para o céu com distribuição dinâmica de luminâncias (DDL), disponibilizado pelo software, para a cidade de Maceió. O céu DDL combina de forma probabilística três tipos de céu padrão CIE (encoberto, parcialmente nublado e claro) usando os estudos de Cabús (2002).

\begin{tabular}{|c|c|c|c|c|c|c|c|c|c|c|c|c|c|c|}
\hline \multirow{3}{*}{ Grupo } & \multirow{3}{*}{ Modelo } & \multicolumn{8}{|c|}{ Características Geométricas } & \multicolumn{5}{|c|}{ Índices avaliados } \\
\hline & & \multicolumn{3}{|c|}{ Ambiente } & \multicolumn{4}{|c|}{ Janela } & \multirow{2}{*}{ Andar } & \multirow{2}{*}{ Ems } & \multirow{2}{*}{ Ums } & \multirow{2}{*}{ IULN } & \multirow{2}{*}{ ESA } & \multirow{2}{*}{$J C P$} \\
\hline & & $\mathrm{C}(\mathrm{m})$ & $L(m)$ & $\mathrm{Pd}(\mathrm{m})$ & $P(m)$ & $A(m)$ & $\mathrm{L}_{\mathrm{j}}(\mathrm{m})$ & Orientação & & & & & & \\
\hline \multirow{6}{*}{1} & $E-1-N$ & \multirow{2}{*}{5,1} & \multirow{2}{*}{6,22} & \multirow{2}{*}{4,37} & 1,95 & & & \multirow{2}{*}{ Sul } & \multirow{7}{*}{ 3은 } & $x$ & $x$ & $x$ & $x$ & $x$ \\
\hline & $\mathrm{E}-1-\mathrm{M}$ & & & & 1,1 & & & & & $x$ & $x$ & $x$ & $x$ & $x$ \\
\hline & $\mathrm{E}-2-\mathrm{N}$ & 524 & 392 & 437 & 1,95 & 12 & 363 & Oecte & & $x$ & $\mathrm{x}$ & $x$ & $\mathrm{x}$ & $x$ \\
\hline & $\mathrm{E}-2-\mathrm{M}$ & S, ८4 & 3,92 & 4,31 & 1,1 & 1,2 & 3,03 & Ueste & & $x$ & $\mathrm{x}$ & $\mathrm{x}$ & $x$ & $x$ \\
\hline & $\mathrm{E}-3-\mathrm{N}$ & 51 & 622 & 437 & 1,95 & & & Nerte & & $\mathrm{X}$ & $\mathrm{X}$ & $\mathrm{x}$ & $\mathrm{x}$ & $\mathrm{x}$ \\
\hline & E-3-M & 3,1 & $0, \angle 2$ & 4,31 & 1,1 & & & INorte & & $x$ & $\mathrm{x}$ & $\mathrm{x}$ & $x$ & $x$ \\
\hline \multirow[b]{2}{*}{2} & $E-4-3 A$ & \multirow[b]{2}{*}{5,24} & \multirow[b]{2}{*}{3,92} & \multirow[b]{2}{*}{4,37} & \multirow[b]{2}{*}{1,1} & \multirow[b]{2}{*}{1,7} & \multirow[b]{2}{*}{2} & \multirow{2}{*}{$\begin{array}{l}\text { Leste (Sem } \\
\text { visão de } \\
\text { céu) }\end{array}$} & & $x$ & $x$ & $x$ & $x$ & - \\
\hline & $E-4-4 A$ & & & & & & & & 40 & $x$ & $x$ & $x$ & $x$ & - \\
\hline
\end{tabular}

A malha de pontos de análise foi definida a partir dos parâmetros disponibilizados na NBR ISO/CIE 8.995-1 (ABNT, 2013b). Os modelos E-1 e E-3 tiveram malhas de $8 \times 8$ pontos, enquanto os demais de $6 \times 8$ pontos.

Os resultados foram analisados em duas etapas, inicialmente o grupo 1 quanto ao desempenho luminoso e à visão de céu dos leitos. Posteriormente o grupo $2 \mathrm{com} \mathrm{a}$ análise apenas da disponibilidade de luz natural. 


\section{Resultados e discussão}

Os grupos foram analisados inicialmente quanto à disponibilidade de luz natural. Para melhorar a compreensão desse aspecto ao longo do ano os resultados foram categorizados por estação do ano para todos os modelos.

\section{Grupo 1: Enfermarias com visão de céu - Métricas de desempenho}

Os resultados para Ems são apresentados na Figura 2. Observa-se que a quantidade de luz natural disponível ao longo de todo o ano é grande, atendendo aos requisitos da ISO CIE 8.995-1 (ABNT, 2013b) quanto à iluminação mínima em enfermarias hospitalares. Observa-se ainda que as janelas voltadas a sul (E-1-N e M) e norte (E-3-N e M) possuem variação significativa entre as estações de primavera/verão e outono/inverno, o que é menos evidente na orientação oeste (E-2-N e M). Esse comportamento já era esperado, tendo em vista a posição da abertura em relação à trajetória aparente do sol na abóbada celeste.

Os resultados para Ums pode ser observada na Figura 3. Os resultados apontam que, para a orientação oeste (E-2-N e M), a Ums se altera em, no máximo, 4,5\% com a mudança da altura da janela, mantendo-se próxima a $65 \%$. Isso se dá tendo em vista que a trajetória do sol ao longo do dia faz com que a abertura receba luz em alturas solares diferentes, iluminando todo o ambiente. A pequena variação da iluminância média, em torno de $1,2 \%$, corrobora com esta afirmação.

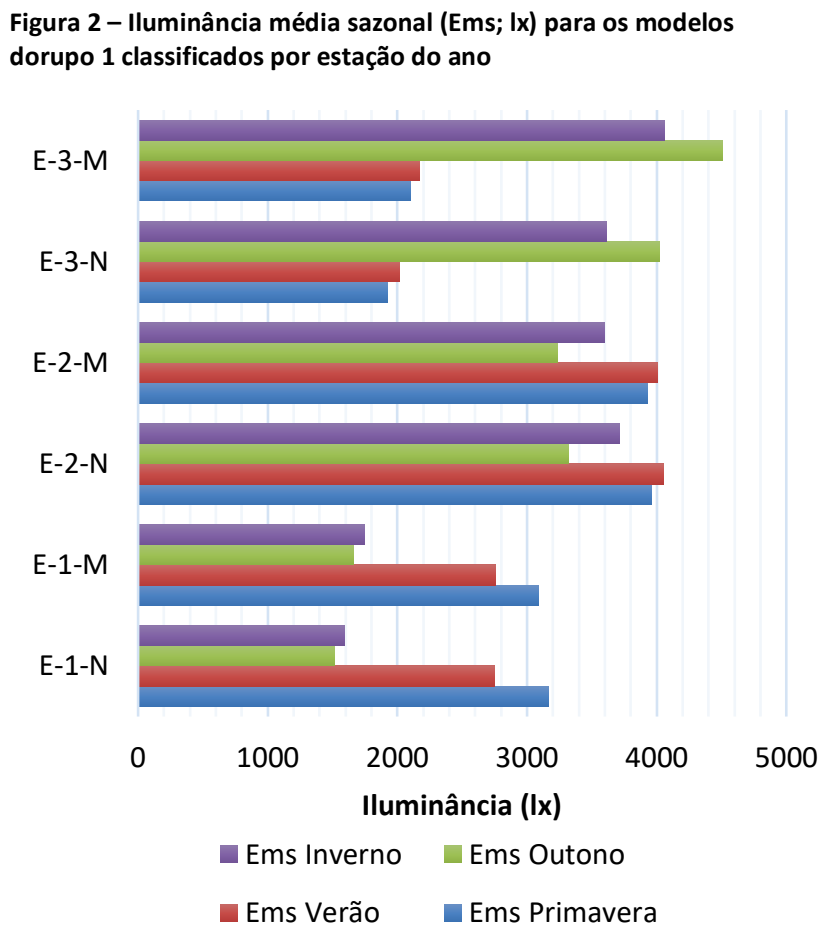

Fonte: os autores.

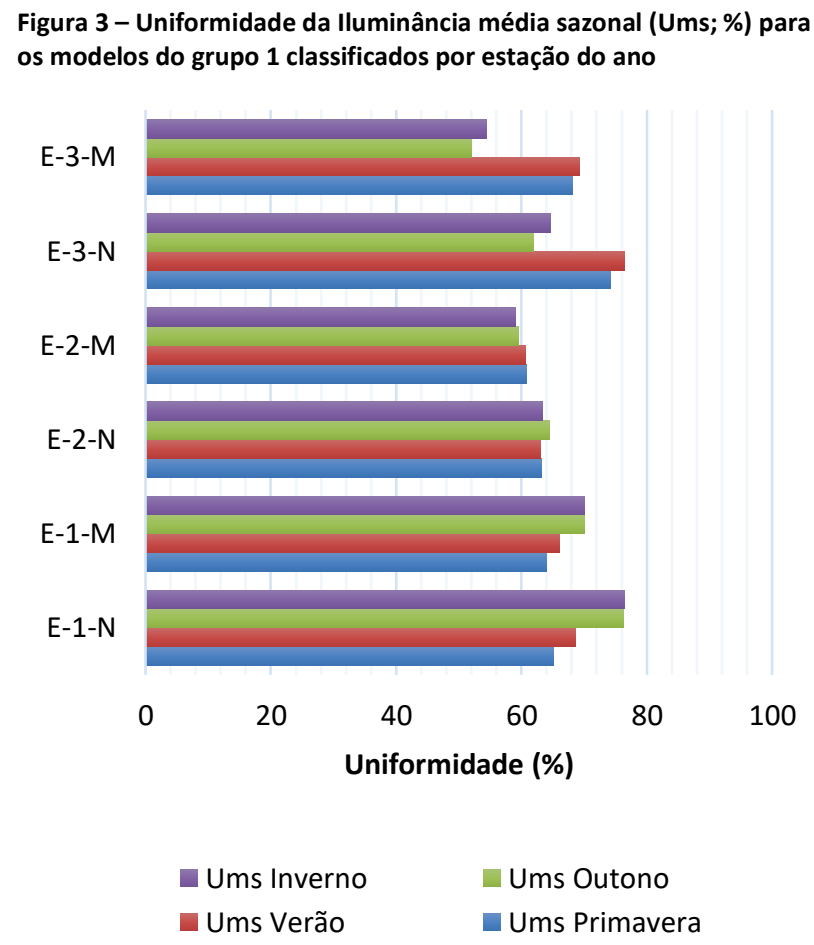

Fonte: os autores.

Nos modelos voltados a norte (E-1-N e M) a janela mais baixa proporcionou maiores valores de Ums que os demais. Tal resultado não se verifica na orientação sul (E-3-N e $M)$, onde aconteceu o efeito inverso. A ocorrência de alturas solares maiores ao longo do ano na orientação norte fez com que a janela alta promovesse maiores valores de uniformidade no ambiente. Na orientação sul o ambiente recebe luz solar direta em porções mais profundas do ambiente, situação indesejada devido à grande possibilidade de ofuscamento e aquecimento, fazendo com que esse parâmetro de análise encontre seus melhores resultados com a janela mais baixa. 
Os efeitos apresentados mostram que para orientações em que a altura solar ao longo do dia é predominantemente grande, como no caso da orientação norte para a cidade de Maceió, é preferível utilizar janelas altas, aumentando a profundidade da incidência de luz direta no ambiente. Na orientação oposta, a janela baixa gera um efeito melhor tanto na iluminância média quanto em sua uniformidade.

A Figura 4 apresenta os valores obtidos para Iluminância Útil de Luz Natural (IULN). Os resultados apresentados mostram um comportamento distinto em todos os modelos. Para a orientação sul (E-1-N e M) há pouca diferença entre os resultados, entretanto há uma predominância de melhores resultados para os períodos de inverno e outubro, onde o intervalo preferível (E3) ocupa mais de $80 \%$ do ano para qualquer altura de janela.

Nos períodos de primavera e verão o intervalo preferível continua predominante, mas se reduz a valores próximos a $60 \%$. Nesse caso há um aumento da faixa de iluminância que deve ser evitada (E4), indicando que nesse período há a probabilidade da ocorrência de ofuscamento, principalmente na posição dos leitos próximos às janelas. A diferença entre os modelos com janela alta e baixa para este período é a que se mostra mais evidente de todos os resultados, sendo a alta a que obtém melhores valores no intervalo preferível (E3).

Figura 4 - Iluminância Útil de Luz Natural (IULN; \%) para os modelos do grupo 1 classificados por estação do ano

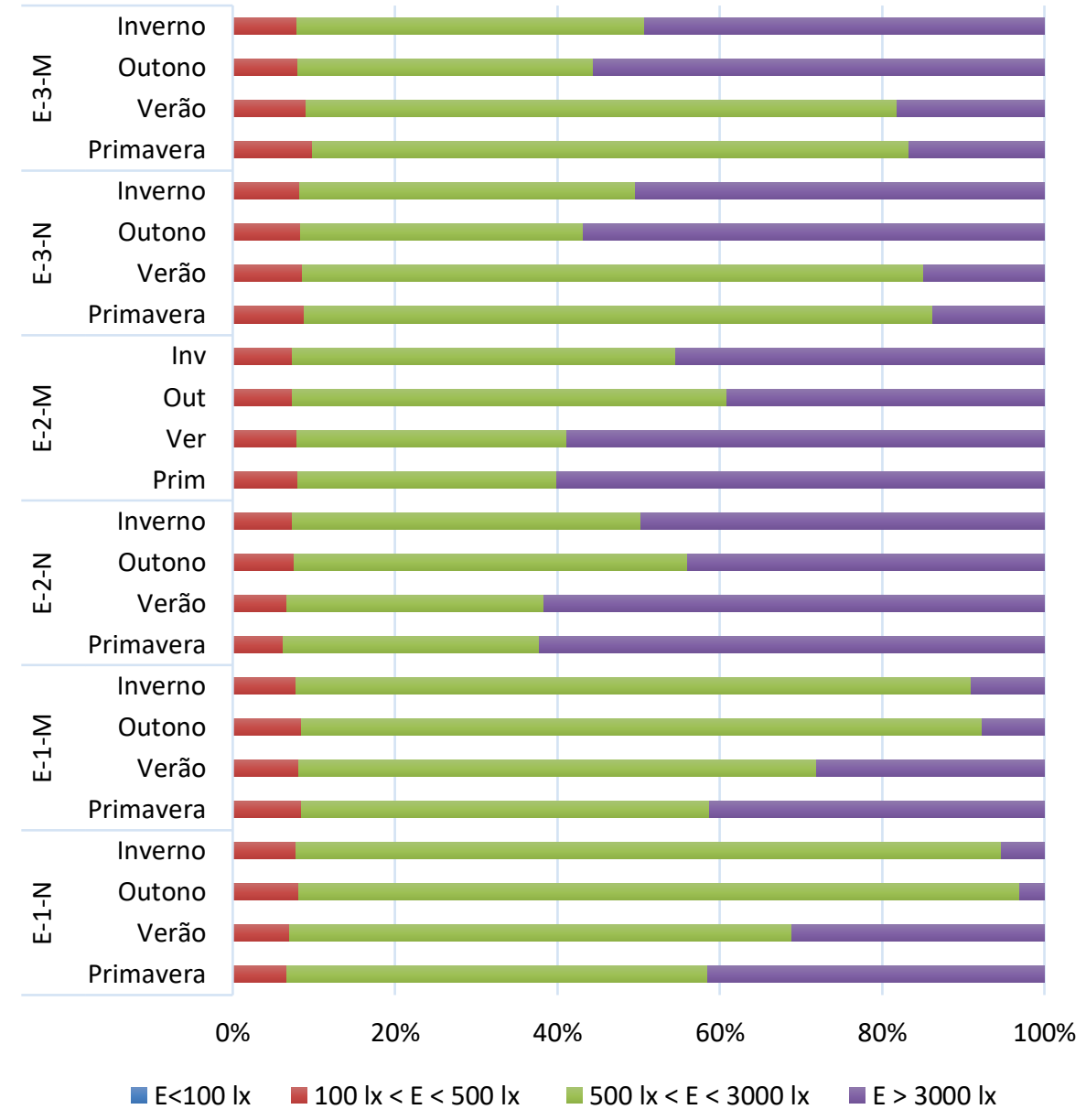

Fonte: os autores.

Na orientação oeste (E-2-N e M) os valores no intervalo a ser evitado (E4) aumentam, tornando-se predominantes nos dois modelos e estações, com valores maiores que 50\%. Esse efeito acontece tendo em vista que os raios solares, por conta da orientação, 
atingem regiões mais profundas do ambiente. Essa conclusão dos resultados pode ser atestada pelos resultados dos modelos com janela mais alta, onde o intervalo E4 contém valores até $4 \%$ maiores que na outra situação.

Nas verificações do Ems e Ums percebeu-se que os comportamentos dos modelos 1 e 3 são opostos, o que se repete na análise da IULN. Para o modelo 3, em que a janela está na orientação norte, os períodos de inverno/outono possuem resultados predominantes no intervalo que deve ser evitado (E4). Nesse período a janela baixa possui os melhores resultados, com até $7 \%$ de valores a mais no intervalo preferível (E3). $\mathrm{Na}$ primavera/verão os resultados são melhores, com maior ocorrência no intervalo preferível (E3) e diferença não significativa entre os modelos com janela alta e baixa.

Os resultados anteriores apontam a grande possibilidade de ocorrência de ofuscamento em todos os modelos. Os resultados da Exposição Solar Anual (ESA), apresentados na Figura 5, reafirmam tal comportamento. Apenas os resultados da orientação sul atingiram o que a LM 83-12 (IES, 2012) define como valores aceitáveis (menores que 3\%). Os demais resultados extrapolam os valores máximos de $7 \%$, classificados como neutros. A pior situação, como já verificado na análise da IULN, encontra-se no modelo orientado a oeste.

Figura 5 - Exposição Solar Anual (ESA) para os modelos do grupo 1. A zona verde indica a faixa de ESA $<3 \%$ (Neutra), a amarela a faixa onde ESA $<7 \%$ (Aceitável), a vermelha para ESA $>10 \%$ (Insatisfatório)

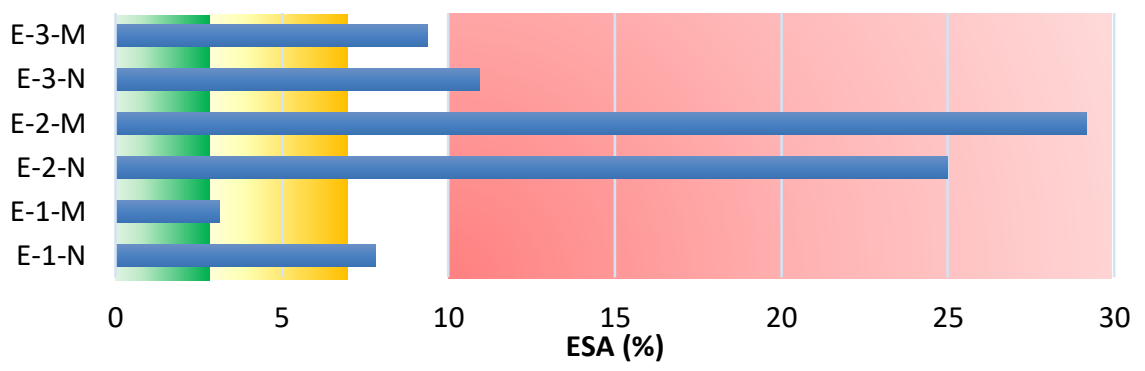

Fonte: os autores.

Todos os resultados apontam para a necessidade da implantação de protetores solares. O grande pé-direito do ambiente aliado ao tamanho das aberturas faz com que a disponibilidade de luz natural seja alta, mas mostra a deficiência na proteção solar em todos os casos do grupo 1.

\section{Grupo 1: Enfermarias com visão de céu - Janela de Céu}

A possibilidade de ocorrência de ofuscamento nos ambientes estudados foi analisada levando-se em consideração a visão de céu do interno deitado no leito. A máscara de visão de céu para a enfermaria 1, com abertura orientada a sul e modelo com janela alta, é apresentada na Figura 6.

Importante notar que todos os leitos possuem visão de céu muito pequena e que aqueles mais distantes da janela são os que estão em situação mais favorável.

Os leitos L1 e L2, com maior visão de céu e mais próximos da janela, possuem ainda uma situação agravante: a porção de céu visível a partir deles coincide com a trajetória solar em um determinado período do ano, o que não acontece com os dois mais ao fundo, para L1 em 1,45\% do ano no período da manhã, e para L2 em 1,42\% no período da tarde, ambos no final do outono e começo do inverno. Esse fato indica que os dois leitos citados estão posicionados de tal forma que, sem proteção solar, poderão ter situações de ofuscamento. Nenhum dos quatro leitos possui visão abaixo da linha do horizonte, fazendo com que o entorno não seja visível. 
RIBEIRO, P. V. S. et al.

Influência do peitoril de janelas na luz natural e visão de céu em enfermarias

Figura 6 - Máscara de visão de céu para os leitos da enfermaria E-1 na situação sem modificação, com janela alta. A mancha escura indica a porção de céu visível; ' $A$ ' o percentual de céu visível e 'I' o percentual anual de insolação direta

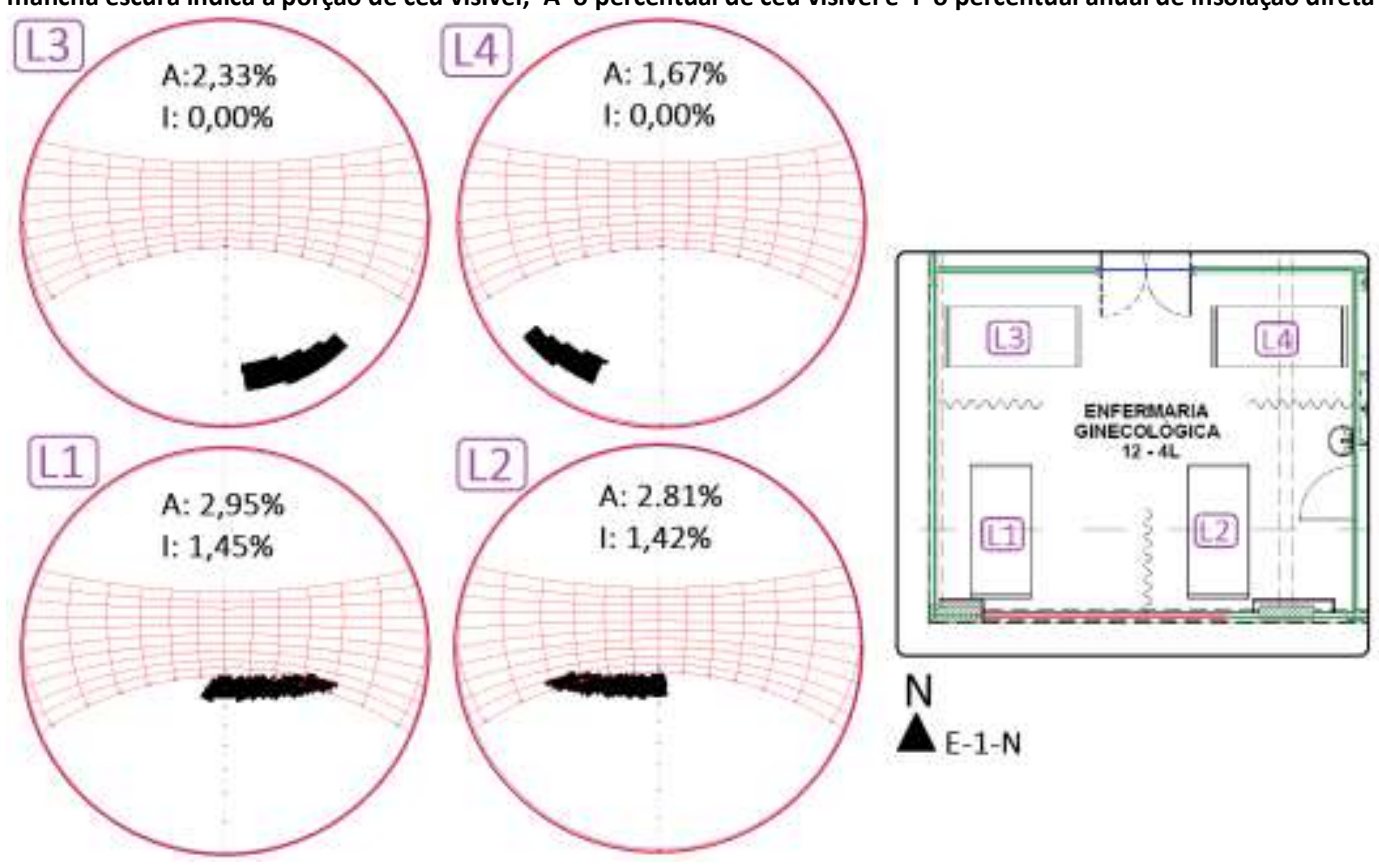

Fonte: os autores.

A janela orientada a sul, como verificada nas inferências anteriores, possui a situação mais agravada quanto à possibilidade de ofuscamento. Nas outras orientações esse efeito é minimizado. Quando a posição da janela é alterada, como mostrado na Figura 7, a área de céu visível nas posições analisadas aumenta. Entretanto, a situação de ofuscamento dos leitos mais próximos à janela permanece e é agravada. Nos leitos mais distantes, contudo, há uma melhora na visão do entorno, onde já é possível visualizar porções de céu mais próximas do horizonte. Há um efeito significativo na área de céu visível quando a dimensão do peitoril da janela é alterada, aumentando a área em até cinco vezes para as posições mais próximas.

Figura 7 - Máscara de visão de céu para os leitos da enfermaria E-1 na situação modificada, com janela baixa. A mancha escura indica a porção de céu visível; ' $A$ ' o percentual de céu visível e ' $l$ ' o percentual anual de insolação direta

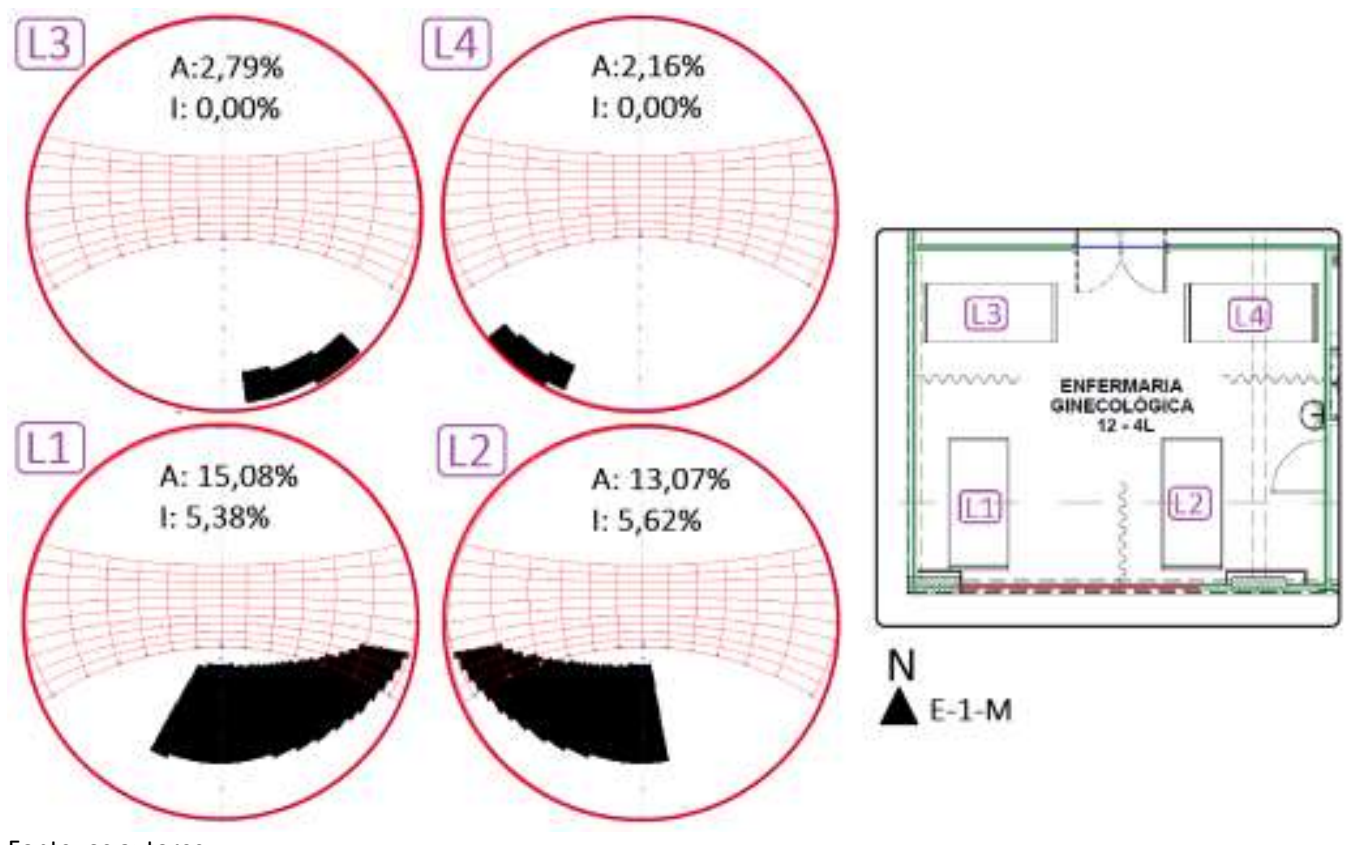

Fonte: os autores. 
RIBEIRO, P. V. S. et al.

Influência do peitoril de janelas na luz natural e visão de céu em enfermarias

Observa-se ainda que os leitos mais próximos da janela terão insolação direta nos períodos de final de outono e começo de inverno. O leito L1 terá insolação em 5,83\% do ano, nas primeiras horas do dia, enquanto o $\mathrm{L} 2$, com $5,62 \%$ do ano, terá insolação direta no final da tarde.

A enfermaria utilizada no modelo 3 é semelhante à do modelo 1 , mas com janela orientada a norte. Os resultados dos modelos com e sem modificação são apresentados nas Figuras 8 e 9, respectivamente.

Figura 8 - Máscara de visão de céu para os leitos da enfermaria E-3 na situação sem modificação, com janela alta. A mancha escura indica a porção de céu visível; ' $A$ ' o percentual de céu visível e ' $I$ ' o percentual anual de insolação direta

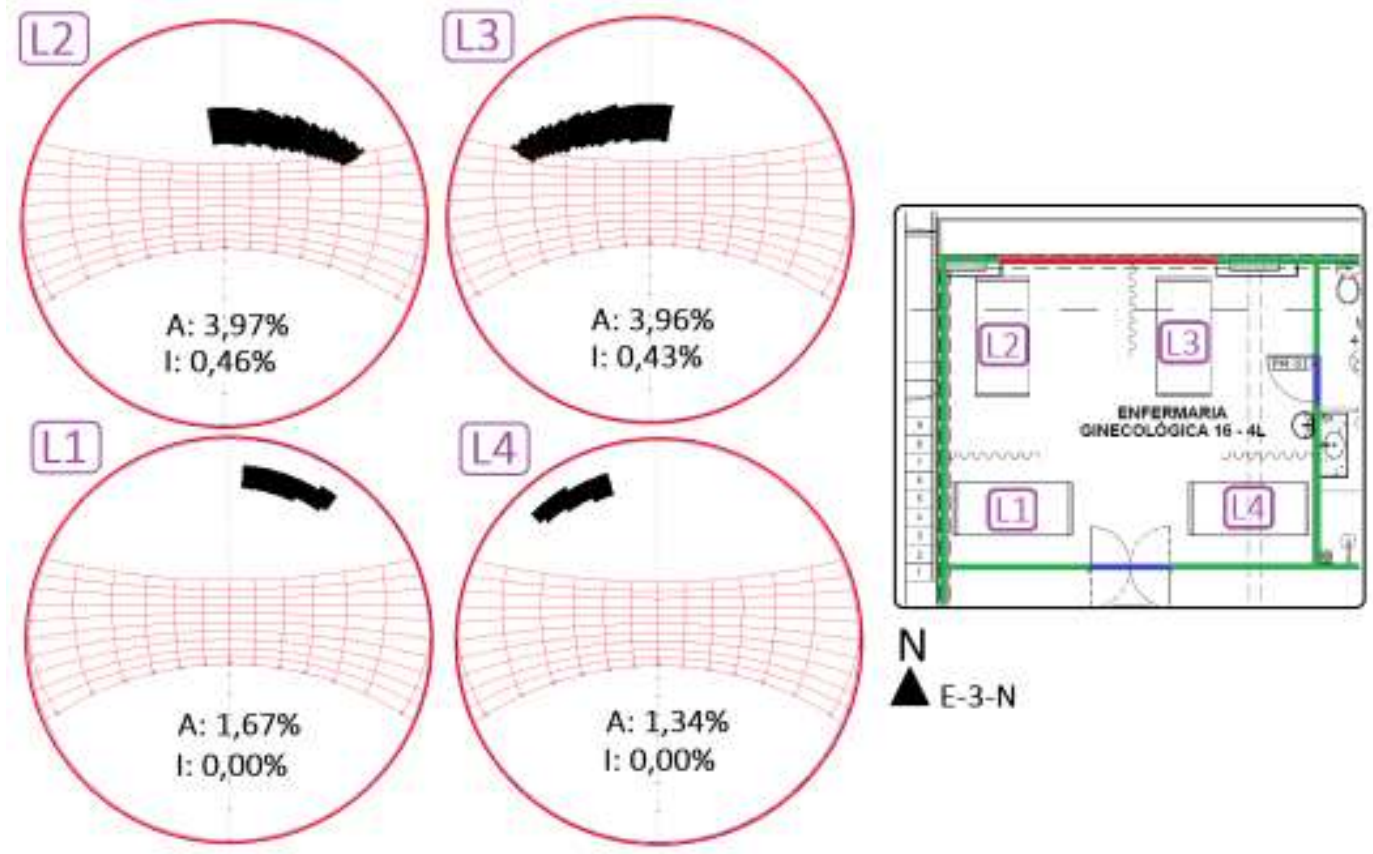

Fonte: os autores.

Figura 9 - Máscara de visão de céu para os quatro leitos da enfermaria E-3 na situação modificada, com janela alta. A mancha escura indica a porção de céu visível; 'A' o percentual de céu visível e 'I' o percentual anual de insolação direta

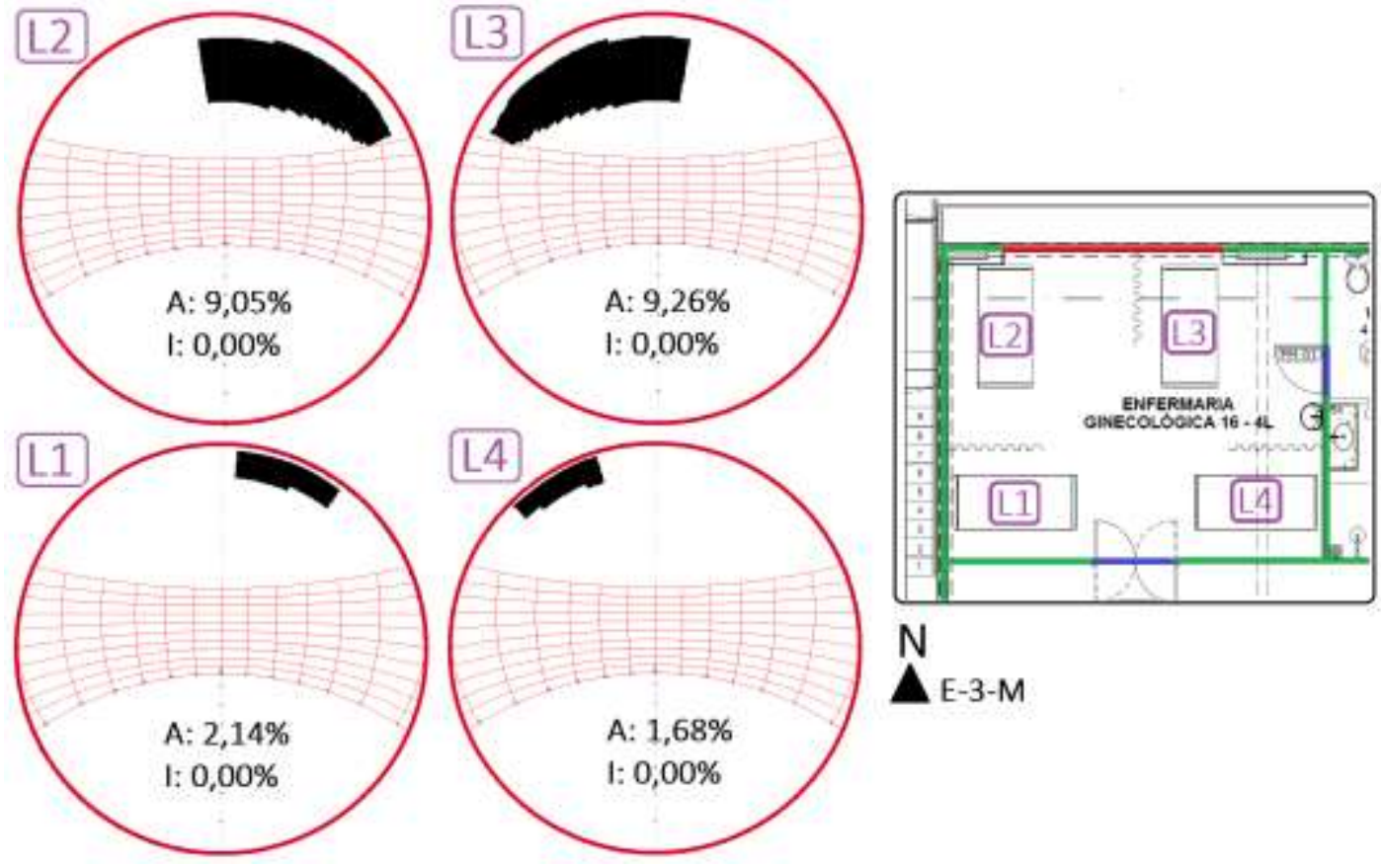

Fonte: os autores. 
Nesse modelo há uma melhor situação quanto à ocorrência de eventos de ofuscamento, tendo em vista que as porções de céu visíveis estão mais distantes da região de trajetória aparente do sol para a cidade de Maceió. Observa-se ainda que a área de visão de céu, tendo em vista o posicionamento do leito, é diferente da situação anterior.

A falta de visão do horizonte permanece, fazendo com que a visão do exterior se restrinja a uma porção do céu. Na Figura 9 é possível observar a mudança na visão de céu com a redução do pé direito da janela. Nesse modelo o ganho é de até 2,3 vezes.

Nas Figuras 10 e 11 estão apresentadas as máscaras de visão de céu para o modelo E-2, com a abertura da enfermaria voltada a oeste. Nesse caso não há ocorrência de ofuscamento na posição dos leitos. As análises anteriores apontaram que haveria entrada de luz solar direta o que, tendo em vista a posição da janela e dos leitos, se restringe à região de circulação.

Figura 10 - Máscara de visão de céu para os dois leitos da enfermaria E-2 na situação sem modificação, com janela alta e na modificada, com janela mais baixa. A mancha escura indica a porção de céu visível; ' $A$ ' o percentual de céu visível e ' $\mathrm{l}$ ' o percentual anual de insolação direta
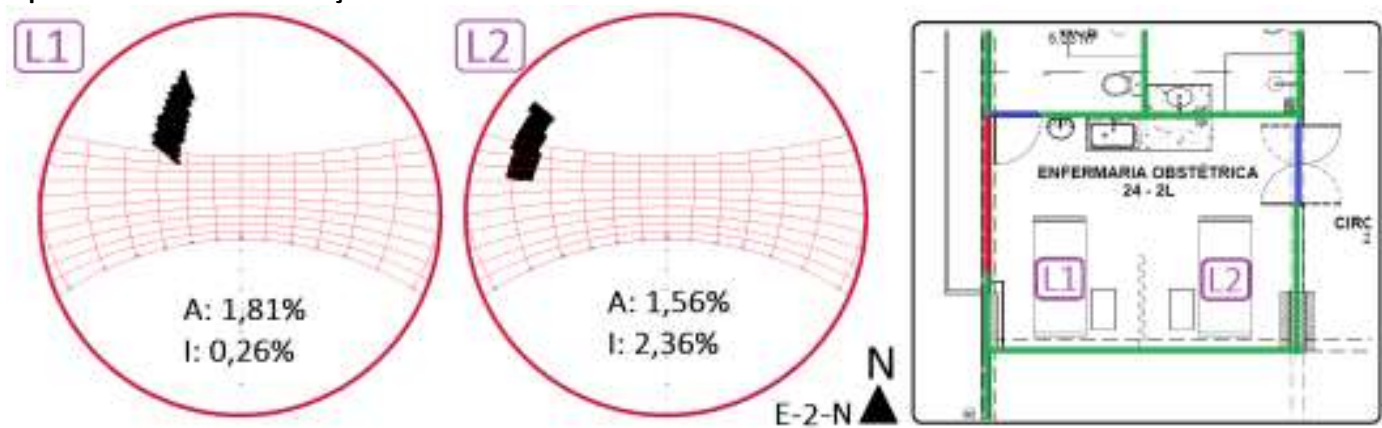

Fonte: os autores.

Figura 11 - Máscara de visão de céu para os dois leitos da enfermaria E-2 na situação modificada, com janela alta e na modificada, com janela mais baixa. A mancha escura indica a porção de céu visível; 'A' o percentual de céu visível e ' $I$ ' o percentual anual de insolação direta

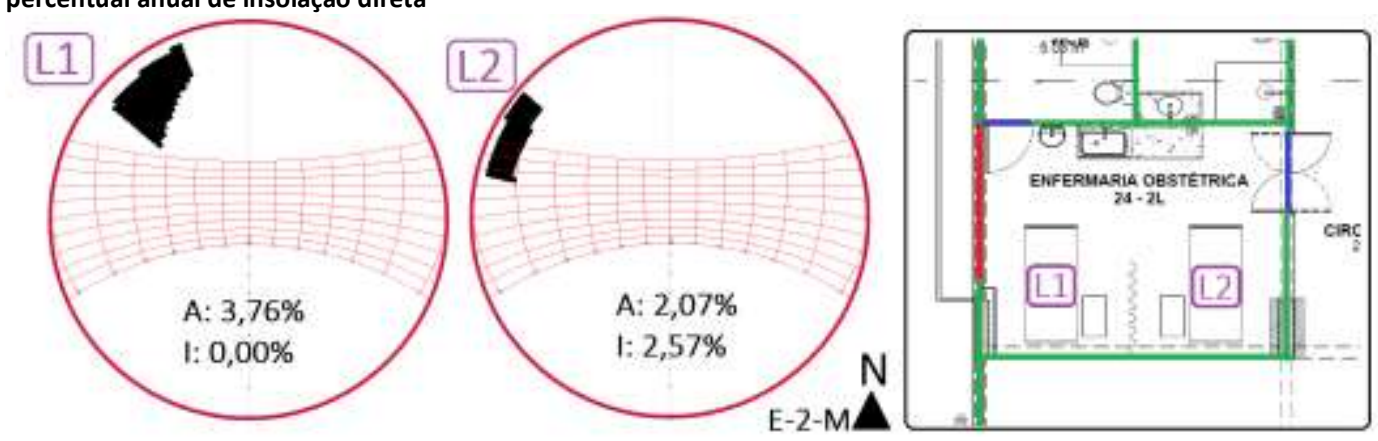

Fonte: os autores.

Em todos os resultados reafirma-se a necessidade da proteção solar externa. Situações com áreas de visão de céu grandes não significam uma situação de conforto. Todos os modelos apresentam situação ruim para o paciente no leito na análise da qualidade da vista, entretanto os modelos com janela baixa apresentam maior possibilidade de visão do entorno.

Grupo 2: Enfermarias sem visão de céu

O segundo grupo de modelos compreende as enfermarias que possuem janela voltada para um vazio interno à edificação. As comparações foram feitas entre os modelos no $3^{\circ}$ (E-4-3A) e no $4^{\circ}$ andar (E-4-4A). Os resultados de Ems estão apresentados na Figura 12. 
A quantidade de luz natural disponível nos ambientes do quarto andar atendem aos valores mínimos necessários para enfermarias, de 100 lx (ABNT, 2013), entretanto, para o terceiro andar nas estações de outono e inverno, a quantidade é insuficiente. A diferença entre os modelos com e sem visão de céu é grande, mas ainda assim são situações que atendem, ou chegam próximo de atender, aos requisitos mínimos. A Ums para o grupo em análise é apresentada na Figura 13.

Figura 12 - Iluminância média sazonal (Ems; Ix) para os modelos do grupo 2, classificados por estação do ano

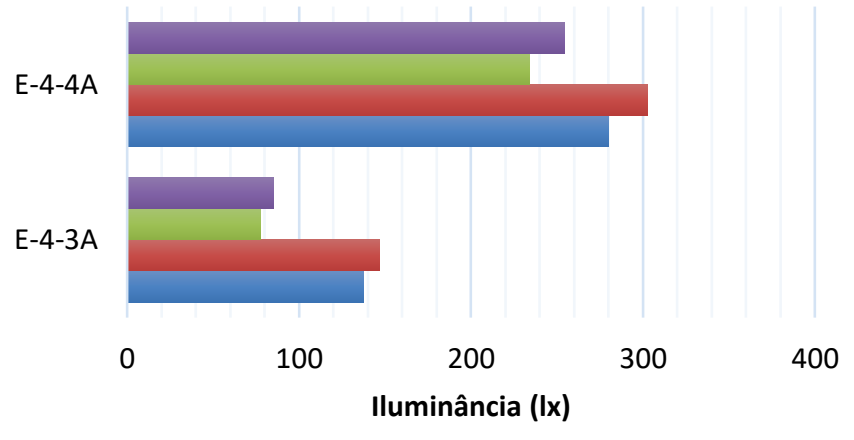

Ems Inverno $\quad$ Ems Outono $n$ Ems Verão $\square$ Ems Primavera

Fonte: os autores.

Figura 13 - Uniformidade da lluminância média sazonal (Ums; \%) para os modelos do grupo 2, classificados por estação do ano.

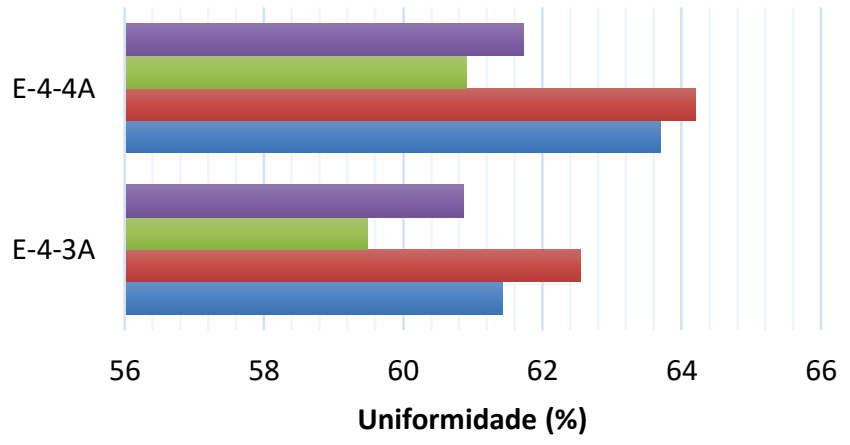

- Ums Inverno —Ums Outono a Ums Verão —Ums Primavera

Fonte: os autores.

O comportamento da Ums é semelhante ao da Ems. Como há pouca entrada de luz natural e nenhuma visão de céu, a grande parcela da luz que entra no ambiente é refletida nas paredes do vazio interno, funcionando como um duto de luz, fazendo com que não haja gradientes de iluminância tão grandes no plano de trabalho. Uma das principais consequências da redução da iluminância no plano de trabalho é a mudança na configuração da IULN, se comparada aos modelos do grupo 1. Os resultados para esse índice são observados na Figura 14.

Observa-se a predominância de valores no intervalo em que a luz é insuficiente para atividades de trabalho (E1). Os piores resultados continuam a aparecer nas enfermarias do terceiro andar. A estação do ano possui pouca influência nos resultados, mesmo assim os períodos de primavera e verão possuem os melhores resultados.

Mesmo com pouca disponibilidade de luz natural, a geometria da janela e do vazio na qual ela está conectada faz com que a quantidade de luz seja suficiente para uso. 
Os ambientes de enfermaria que possuem janelas altas influenciaram de forma positiva quanto à disponibilidade de luz natural, promovendo ao acamado uma visão de exterior apenas do céu. A combinação de pé direito e peitoril altos das janelas fez com que o desempenho da iluminação natural fosse além do necessário para o ambiente. Tal excesso indica que haverá a possibilidade de ofuscamento para os usuários nos leitos.

Figura 14 - Iluminância Útil de Luz Natural (IULN, \%) para os modelos do grupo 2, classificados por estação do ano

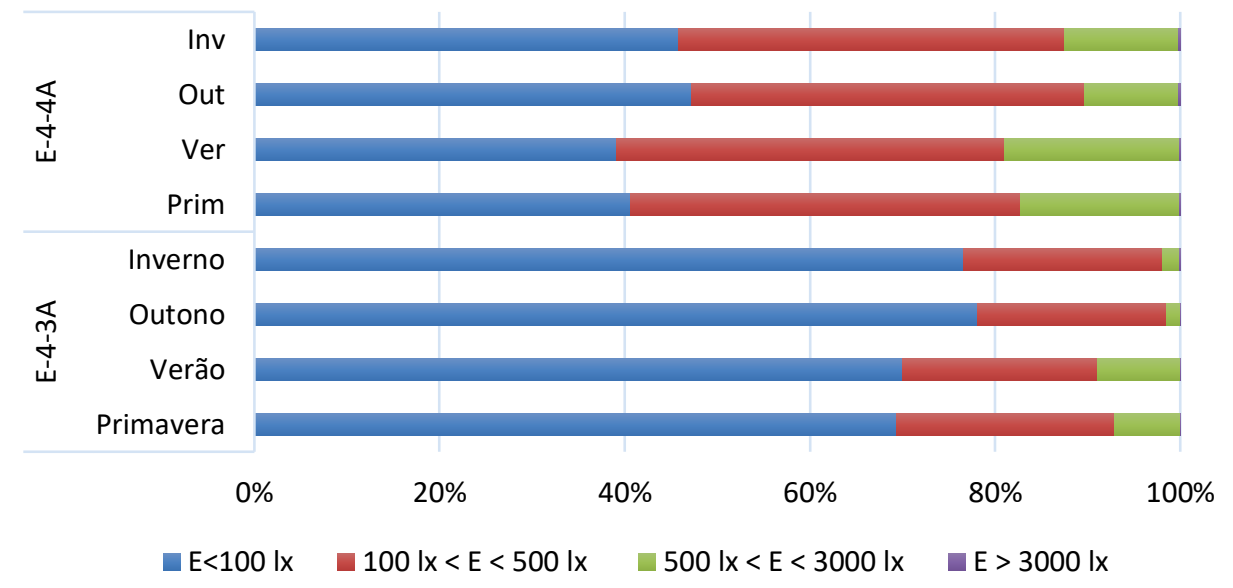

Fonte: os autores.

Para a fachada sul os ambientes com janelas altas obtiveram melhores resultados de Ems, Ums e IULN, mas na análise da ESA os melhores resultados foram obtidos na situação modificada, com janelas altas. Resultado inverso pode ser observado para a abertura na orientação norte. Para a orientação oeste os valores tendem a ser mais significativos quanto à entrada de luz solar direta, tendo em vista a geometria da insolação ao longo do ano.

$\mathrm{Na}$ análise da visão de céu observa-se que nenhum dos ambientes consegue fornecer para o usuário no leito visão do horizonte e, consequentemente, do entorno. A redução da altura do peitoril da janela faz com que a área de céu visível aumente; entretanto, esta ampliação faz com que aumente a possibilidade de ofuscamento. A janela alta faz com que a porção de céu vista a partir do leito seja próxima ao zênite, agravando a possibilidade da entrada de luz solar direta.

$\mathrm{Na}$ análise dos ambientes voltados para o vazio interno à edificação observa-se que, mesmo sem visão de céu, a iluminância é suficiente para as atividades desenvolvidas. A disponibilidade de luz natural atingiu valores muito próximos ao mínimo tolerável, mostrando a necessidade de melhorias na captação da luz natural. A ausência de visão do entorno pode aumentar a percepção de eventos de ofuscamento gerados pela grande quantidade de luz próxima à janela, como abordado anteriormente, o que reforça a necessidade de realização de estudos diretamente com os pacientes.

\section{Conclusão}

A avaliação do desempenho luminoso de ambientes hospitalares ainda carece de muitos parâmetros de análise, tanto em relação à adequação dos já existentes ao ambiente estudado quanto ao desenvolvimento de parâmetros específicos, entretanto as ferramentas computacionais disponíveis atualmente permitem que diversas verificações quantitativas possam ser realizadas. O objeto de estudo, enfermaria, possui características como a altura das aberturas e a disposição dos leitos que vêm sendo repetidas em outras instituições de uso hospitalar na cidade. 
Projetos de edifícios hospitalares devem considerar o dimensionamento e a localização das aberturas que possibilitem visão do exterior, identificando, além da visão do céu, a possibilidade de ofuscamento do acamado em função da altura do peitoril, orientação da abertura e altura do pé direito do ambiente. Quando esta relação não é favorável, deve-se priorizar o uso de protetores solares para reduzir a lluminância média do ambiente, garantindo uma boa uniformidade luminosa no interior destes espaços.

Para o estudo a modificação proposta, de redução da altura do peitoril, permitiu que o paciente deitado tivesse maior visão de céu que na situação anterior, com peitoril alto. A quantidade de insolação direta que o paciente recebe é alterada, quando da modificação da altura do peitoril, principalmente nas macas próximas à janela. Em alguns casos, como na enfermaria 1, há aumento no período de insolação, enquanto que nos demais houve redução.

A presença de janelas em ambientes hospitalares é importante para as funções psicológicas, físicas e fisiológicas do ser humano, contribuindo para o bem estar e o conforto visual do usuário, bem como na sua recuperação. Entretanto, a presença de luz direta do céu e do sol pode trazer danos, como o ofuscamento. Para o presente objeto de estudo, observa-se a necessidade da presença de protetores solares, a exemplo de brises fixos ou móveis, para o controle da luz direta do céu ou do sol.

A qualidade da visão externa não foi analisada neste trabalho, tendo em vista a utilização de simulação computacional. O trabalho limita-se a avaliar o conforto luminoso em seu aspecto quantitativo.

\section{Agradecimentos}

Agradecimentos ao Grupo de Pesquisa em lluminação (GRILU), da Universidade Federal de Alagoas (UFAL). O presente trabalho foi realizado com apoio da Coordenação de Aperfeiçoamento de Pessoal de Nível Superior Brasil (CAPES) e do Conselho Nacional de Desenvolvimento Científico e Tecnológico (CNPq).

\section{Notas}

(1) Artigo original: "LOE, D.; DAVIDSON, P. (1998) A holistic approach to lighting design. European Diretory of Suitable Efficient Building, London, p.130-137"

(2) https://tribunahoje.com/noticias/cidades/2018/01/22/hospital-da-mulher-deve-ser-entregue-ate-junho/

\section{Referências}

ABNT - ASSOCIAÇÃO BRASILEIRA DE NORMAS TÉCNICAS. ABNT NBR 15215-2: lluminação Natural Parte 2: Procedimentos de Cálculo para a Estimativa da Disponibilidade de Luz Natural. 1 ed. Rio de Janeiro: ABNT, 2005a. 17 p.

ABNT - ASSOCIAÇÃO BRASILEIRA DE NORMAS TÉCNICAS. ABNT NBR 15215-3: lluminação Natural Parte 3: Procedimentos de Cálculo para a Determinação da lluminação Natural em Ambientes Internos. 1 ed. Rio de Janeiro: ABNT, 2005b. 33 p.

ABNT - ASSOCIAÇÃO BRASILEIRA DE NORMAS TÉCNICAS. ABNT NBR 15215-4: lluminação Natural Parte 4: Verificação Experimental das Condições de lluminação Interna de Edificações - Método de Medição. 1 ed. Rio de Janeiro: ABNT, 2005c. 13 p.

ABNT - ASSOCIAÇÃO BRASILEIRA DE NORMAS TÉCNICAS. ABNT NBR 15575-1: Edificações Habitacionais Desempenho - Parte 1: Requisitos Gerais. 1 ed. Rio de Janeiro: ABNT, 2013a. 60 p.

ABNT - ASSOCIAÇÃO BRASILEIRA DE NORMAS TÉCNICAS. ABNT NBR ISO/CIE 8995-1: lluminação de Ambientes de Trabalho - Parte 1: Interior. 1 ed. Rio de Janeiro: ABNT, 2013b. 54 p. 
BAKER, N.; FANCHIOTTI, A.; STEEMERS, K. Daylight in Architecture: a European Reference Book. 2. ed. Bruxelas: James \& James, 1998. 384 p.

BAKER, N.; STEEMERS, K. Daylight Design of Buildings. Londres: James \& James, 2002. 247 p.

BOYCE, P. R. Human Factors in Lighting. 2. ed. Londres: Taylor and Francis, 2003. 681 p.

BOYCE, P. R. Review: the impact of light in buildings on human health: The Impact of Light in Buildings on Human Health. Indoor and Built Environment, v. 19, n. 1, p. 8-20, fev. 2010. DOI:http://dx.doi.org/10.1177/1420326x09358028.

CABÚS, R. C. Tropical Daylighting: Predicting Sky Types and Interior Illuminance in North-East Brazil. 2002. 288 f. Tese (Doutorado em Arquitetura) - University of Sheffield, Sheffield, 2002.

COSTI, M. A luz em estabelecimentos de saúde. In: ENCONTRO LATINO-AMERICANO DE CONFORTO NO AMBIENTE CONSTRUÍDO, 3. \& ENCONTRO NACIONAL SOBRE CONFORTO NO AMBIENTE CONSTRUÍDO, 6., 2001 , São Pedro. Anais [...]. Porto Alegre: ANTAC, 2001. p. 1-8.

DIAS, A. R. D.; CARVALHO, J. P. V.; HAZBOUN, V. D.; PEDRINI, A. Influência de Métricas Dinâmicas na Avaliação do Aproveitamento da Luz Natural em Clima Tropical. Ambiente Construído, v. 18, n. 3, p. 29-47, set. 2018. FapUNIFESP (SCiELO). DOI:http://dx.doi.org/10.1590/s1678-86212018000300266.

EISAZADEH, N.; ALLACKER, K.; TROYER, F. de. Impact of Window Systems on Daylighting Performance, Visual Comfort and Energy Efficiency in Patient Rooms. In: IBPSA INTERNATIONAL CONFERENCE, 16., 2019, Roma. Proceedings [...]. Roma: IBPSA, 2019. p. 1207-1215.

FERNANDES, J. Código de Obras e Edificações e edificações do DF: inserção de conceitos bioclimáticos, conforto térmico e eficiência energética. 2009. 186 f. Dissertação (Mestrado em Arquitetura e Urbanismo) - Programa de Pósgraduação em Arquitetura e Urbanismo, Universidade de Brasília, Brasília, 2009.

FERNANDES, J. Qualidade da iluminação natural e o projeto arquitetônico: a relação da satisfação do usuário quanto à vista exterior da janela e a percepção do ofuscamento. 2016. 337 f. Tese (Doutorado em Arquitetura e Urbanismo) - Programa de Pós-graduação em Arquitetura e Urbanismo, Universidade de Brasília, Brasília, 2016.

FOUCAULT, M. O Nascimento da Clínica. Tradução: Roberto Machado. Rio de Janeiro: Forense-Universitária, 1977. $241 \mathrm{p}$.

FOUCAULT, M. Microfísica do Poder. 4. ed. Rio de Janeiro: Graal, 1984. 111 p.

GHISI, E.; TINKER, J.; IBRAHIM, S. Área de Janela e Dimensões de Ambientes para lluminação Natural e Eficiência Energética: Literatura Versus Simulação Computacional. Ambiente Construído, Porto Alegre, v. 5, n. 4, p.81-93, jun. 2005.

HELLINGA, H. Daylight and View: The Influence of Windows on the Visual Quality of Indoor Spaces. 2013. 379 f. Tese (Doutorado em Engenharia Estrutural), Delft University of Technology, Delft, 2013.

HOPKINSON, J; PETHERBRIDGE, P; LONGMORE, J. Iluminação Natural. Tradução: Antônio Sarmento Lobato de Faria. 2. ed. Lisboa: Fundação Calouste Gulbenkian, 1975.

IES - ILLUMINATING ENGINEERING SOCIETY. IES LM-83-12: Approves Method: IES Spatial Daylight Autonomy (sDA) and Annual Sunlight Exposure (ASE). 1 ed. Nova York: IES, 2012. 22 p.

KREMER, A. A influência de elementos de obstrução solar no nível e na distribuição interna de iluminação natural em escolas. 2002. 209 f. Dissertação (Mestrado em Engenharia Civil) - Programa de Pós-Graduação em Engenharia Civil, Universidade Federal de Santa Catarina, Santa Catarina, 2002.

LAM, M. Perception and Lighting as Formgivers for Architecture. Nova York: McGraw-Hill, 1997. 318 p. 
LAMBERTS, R.; DUTRA, L.; PEREIRA, F. O. R. Eficiência Energética na Arquitetura. 3. ed. São Paulo: ProLivros, 2014. $366 p$.

LEDER, S. M. Ocupação urbana e luz natural: Proposta de Parâmetro de Controle da Obstrução do Céu para Garantia da Disponibilidade à Luz Natural. 2007. 240 f. Tese (Doutorado em Engenharia Civil) - Programa de Pósgraduação em Engenharia Civil, Universidade Federal de Santa Catarina, Florianópolis, 2007.

LIMA, M. Percepção Visual Aplicada a Arquitetura e à Iluminação. Rio de Janeiro: Ciência Moderna, 2010. 160 p.

MALKIN, J. Hospital Interiors Architecture: Creating Healing Environments for Special Patient Populations. New York: John Wiley, 1992. 144 p.

MANGKUTO, R. A.; ROHMAH, M.; ASRI, A. D. Design Optimization for Window Size, Orientation, and Wall Reflectance with Regard to Various Daylight Metrics and Lighting Energy Demand: a case study of buildings in the tropics: A case study of buildings in the tropics. Applied Energy, v. 164, p. 211-219, fev. 2016.

DOI:http://dx.doi.org/10.1016/j.apenergy.2015.11.046.

MARDALJEVIC, J.; ANDERSEN, M.; ROY, N.; CHRISTOFFERSEN, J. Daylighting Metrics for Residential Buildings. In: SESSION OF THE CIE, 27., 2011, Sun City. Proceedings [...]. Sun City: CIE, 2011. p. 1-19.

MARDALJEVIC, J.; ANDERSEN, M.; ROY, N.; CHRISTOFFERSEN, J. Daylight metrics: is there a relation between Useful Daylight Illuminance and Daylight Glare Probability?. In: BUILDING SIMULATION AND OPTIMIZATION CONFERENCE, 1., 2012, Loughborough. Proceedings [... ]. Loughborough: IBPSA, 2012. p. 189-196.

MARTAU, B. A Luz Além da Visão: Iluminação e sua Relação com a sua Saúde e Bem-Estar de Funcionárias de Lojas de Rua e de Shopping Centers em Porto Alegre. 2008. 504 f. Tese (Doutorado em Arquitetura e Urbanismo) Programa de Pós-graduação em Arquitetura e Urbanismo, Universidade Estadual de Campinas, Campinas, 2008.

MEDEIROS, R. C. B. Avaliação do Desempenho Luminoso de Protetores Solares Verticais na Iluminação Natural em Ambiente de Internação Hospitalar. 2015. 135 f. Dissertação (Mestrado em Dinâmicas do Espaço Habitado) Faculdade de Arquitetura e Urbanismo, Programa de Pós-Graduação em Arquitetura e Urbanismo, Universidade Federal de Alagoas, Maceió, 2015.

MIQUELIN, L. Anatomia dos Edifícios Hospitalares. São Paulo: Cedas, 1992. 241 p.

MONTEIRO, M. Saúde e Açúcar: História, Economia e Arquitetura do Hospital do Açúcar de Alagoas 1950-1990. 2001. 350 f. Tese (Doutorado em Ciências Humanas) - Programa de Pós-graduação em Filosofia, Letras e Ciências Humanas, Universidade de São Paulo, São Paulo, 2001.

NABIL A.; MARDALJEVIC, J. Useful daylight illuminance: A New Paradigm for Assessing Daylight in Buildings. Lighting Research \& Technology, v. 37, n. 1, p. 41-57, mar. 2005. DOI: http://dx.doi.org/10.1191/1365782805li1280a.

PECCIN, A. Iluminação Hospitalar: Estudo de Caso: Espaços de Internação e Recuperação. 2002. 185 f. Dissertação (Mestrado em Arquitetura) - Programa de Pós-Graduação em Arquitetura, Universidade Federal do Rio Grande do Sul, Porto Alegre, 2002.

RASMUSSEN, S. E. Arquitetura vivenciada. São Paulo: Martins Fontes, 2002.

SANTOS, D. M. L. Encontros e Desencontros da Iluminação Natural: Um Estudo em Espaços de Internação Hospitalar. 2009. 165 f. Dissertação (Mestrado em Arquitetura e Urbanismo) - Programa de Pós-Graduação em Arquitetura e Urbanismo, Universidade Federal de Alagoas, Maceió, 2009.

TOLEDO, L. Uma novidade antiga, a busca pela humanização. In: CONGRESSO BRASILEIRO DA ABDEH, 2., 2006, Rio de Janeiro. Anais [...]. Rio de Janeiro: Associação Brasileira para o Desenvolvimento do Edifício Hospitalar, 2006. p. $1-35$. 
RIBEIRO, P. V. S. et al.

Influência do peitoril de janelas na luz natural e visão de céu em enfermarias

ULRICH, R. S. View Through a Window May Influence Recovery from Surgery. Science, v. 224, n. 4647, p. 420-421, 27 abr. 1984. DOI:http://dx.doi.org/10.1126/science.6143402.

ULRICH, R. S. Health Benefits of Gardens in Hospitals. In: PLANTS FOR PEOPLE: INTERNATIONAL EXHIBITION

FLORIADE, 2002, Haarlemmermeer. Proceedings [...]. Haarlemmermeer: BIE, 2002. p. 1-10.

\section{${ }^{1}$ Pedro Vitor Sousa Ribeiro}

Engenheiro Civil. Mestre. Doutorando do Programa de Pós-Graduação Dinâmicas do Espaço Habitado (DEHA UFAL). Professor da Universidade Federal de Sergipe (UFS). Endereço postal: Av. Lourival de Melo Mota, s/n, Tabuleiro dos Martins, Maceió- AL, CEP: 57072-900

\section{${ }_{2}^{2}$ Danielle Maria Lamenha Santos}

Arquiteta e Urbanista. Mestre. Doutoranda do Programa de Pós-Graduação Dinâmicas do Espaço Habitado (DEHA UFAL). Professora da Universidade Federal de Alagoas (UFAL). Endereço postal: Av. Lourival de Melo Mota, s/n, Tabuleiro dos Martins, Maceió- AL, CEP: 57072-900

\section{Lara Torres de Melo Vasconcellos}

Arquiteta e Urbanista. Especialista. Mestranda do Programa de Pós-Graduação Dinâmicas do Espaço Habitado (PPGAU -DEHA). Endereço postal: Av. Lourival de Melo Mota, s/n, Tabuleiro dos Martins, Maceió- AL, CEP: $57072-$ 900

\section{Fernando A de M Sá Cavalcanti}

Arquiteto e Urbanista. Doutor. Professor da Faculdade de Arquitetura e Urbanismo (PPGAU) da Universidade Federal de Alagoas (UFAL). Endereço postal: Av. Lourival de Melo Mota, s/n, Tabuleiro dos Martins, Maceió- AL, CEP: $57072-900$

\section{Ricardo Carvalho Cabús}

Engenheiro Civil. Doutor. Professor Titular do Centro de Tecnologia e do Programa de Pós-Graduação em Arquitetura e Urbanismo (PPGAU) da Universidade Federal de Alagoas (UFAL), Grupo de Pesquisa em Iluminação GRILU. Endereço postal: Av. Lourival de Melo Mota, s/n, Tabuleiro dos Martins, Maceió- AL, CEP: $57072-900$ 